\title{
A review on the concept of consumer innovativeness
}

\author{
Han Pan ${ }^{1, *}$, Wu Xin ${ }^{2}$, Yuping $\mathrm{Li}^{3}$ \\ ${ }^{123}$ Department of Marketing, Chongqing Technology and Business University, Nanan, Chongqing, China
}

\begin{abstract}
Beginning in the 1970s, academia began to study consumer innovation and used it as an important indicator for predicting consumers' new product adoption behavior. This article makes a more comprehensive summary and evaluation of the definition of consumer innovation from three aspects (innate innovativeness; special fields innovativeness; actualized innovativeness), summarizes the relationship between the three innovations, and builds a consumer innovation integration model.
\end{abstract}

\section{Introduction}

Innovation is the driving force for the continuous development of enterprises, and the market launch of new products is the key factor to determine the development of enterprises. However, most of the new products fail in the initial stage of the product diffusion life cycle. The main reason for these failures is that marketers can't meet the needs of different consumers. Therefore, market segmentation and target positioning for innovative products are crucial. How to distinguish and identify early adopters and late adopters, and how to adopt marketing strategies to attract early adopters, has become an important research issue in the field of marketing.

At present, there is no consensus on the definition of consumer innovativeness in academia. From different perspectives, according to the level of abstraction, this paper summarizes consumer innovativeness into three concepts: (1) innate innovativeness. (2) special fields innovativeness (3) actualized innovativeness. Reviewing the previous literature, the research on consumer innovativeness in academia is mainly divided into the measurement scale of consumer innovativeness, the influencing factors of consumer innovativeness, and the relationship between consumer innovativeness and innovativeness behavior. At present, the existing literature has not clarified the relationship among the three concepts of consumer innovativeness, and has not clarified the three concepts separately when summarizing the causes and consequences of consumer innovativeness. In this paper, the concept of domestic and foreign consumers of different innovative systematic review, aiming to clarify the relationship among innate innovativeness, innovativeness in special fields and actual innovativeness, and to summarize the basic viewpoints and influencing factors of the three concepts.

\section{Innovativeness}

\section{1. definition of innate innovativeness}

Consumer innovativeness is regarded as a personality trait, which is called innate innovativeness. It refers to the inherent personality traits of consumers who are willing to pursue and accept new products and new things ${ }^{[1]}$. Midgley and Dowling ${ }^{[2]}$ first proposed innate innovativeness from the perspective of psychological characteristics and social characteristics, and defined it as "the degree to which an individual makes innovativeness decisions independently of others' exchange of experience". The scholar believes that all members of the society have the level of innovativeness, and this innate personality trait is unchanged, and will not be affected by product attributes and others.

\section{2 influencing factors of innate innovativeness}

\subsubsection{Demographic characteristics}

Social demography has been widely studied in all consumer based research, and the influencing factors of consumer innovativeness are no exception. Scholars first consider the antecedents of innate innovativeness from demographic variables, mainly including gender, age, income, education level, family size and so on.

In terms of gender and age, most research results show that age is negatively correlated with innate innovativeness ${ }^{[3]}$. Venkatraman and Price found that gender has a significant impact on cognitive innovativeness ${ }^{[6]}$, but the correlation between gender and cognitive innovativeness is weak. However, the relationship between age and innate innovativeness is on the contrary. The perceived innovativeness of young consumers is significantly higher than that of old consumers, but there is no significant difference in 
cognitive innovativeness. In terms of income and education level, many scholars have proved that they have no significant impact on innate innovativeness ${ }^{[4]}$. Steenkamp and Burgess found that among the three main ethnic groups of consumers in South Africa (white, black and other colored races), the income of innovative consumers is higher than that of non innovative consumers $^{[4]}$. The reason for the two different results may lie in the different dimensions of innate innovativeness. For the two dimensions of consumer innovativeness (cognitive innovativeness and perceived innovativeness), the study found that income was positively correlated with cognitive innovativeness, but not with perceived innovativeness ${ }^{[6]}$.

\subsubsection{Social factors}

Individual personality and behavior are also regulated and influenced by cultural environment. Tellis found that consumers in different countries have different desire for new products, which may be affected by different social and cultural factors ${ }^{[5]}$. Hofstede proposed three dimensions of national culture related to innate innovativeness: individualism, uncertainty avoidance and masculinity ${ }^{[6]}$. On this basis, Steenkamp ${ }^{[4]}$ studied the antecedents of innate innovativeness in the transnational context: (1) individualism. In individualistic society, individuals tend to make decisions and take actions independently of others. (2) Uncertainty avoidance. In countries with high uncertainty aversion rate, people are reluctant to change their existing consumption habits. Therefore, the higher the uncertainty aversion rate, the lower the innate innovativeness of consumers. (3) Masculine. The masculine society pays more attention to wealth, success, material and achievement. Purchasing new goods is a way for individuals to protect their own interests and show off their wealth ${ }^{[7]}$. Therefore, the more masculine the country is, the higher the innate innovativeness of consumers is.

\section{3 special fields innovativeness}

\section{1 definition of special fields innovativeness}

Considering the different preferences of consumers for product types, consumer innovativeness is called special domain innovativeness, which reflects the trend of consumers adopting new products in the special preference domain, and this trend may not be transferred to other categories of products. The research of this definition believes that the attributes related to new products will affect consumer innovativeness, and innovators in one field may show low innovativeness in another product field. For example, a consumer who is more innovative in the field of electronic products may show less interest in other product categories.

\section{2 influencing factors of special fields innovativeness}

Special product preferences are often studied together with innovativeness in special fields. Goldsmith and Flynn classified consumers according to the increase of shopping times and spending ${ }^{[8]}$. The results showed that product involvement and product knowledge had strong and positive correlation with innovativeness in special fields. Citrin proved that there is a strong correlation between the use of related products and innovativeness in specific areas ${ }^{[9]}$. Many follow-up studies have also confirmed this point ${ }^{[10]}$. In addition, product brand attitude and consumer purchase intention also significantly affect innovativeness in specific areas ${ }^{[11]}$. In a word, product involvement, product knowledge, product brand attitude, purchase intention and related product use are the main variables that affect innovativeness in special fields.

\section{Actualized innovativeness}

From the perspective of behavioral science, consumer innovativeness is called actual innovativeness, which refers to the extent to which consumers search for information about new products and purchase new products $^{[13]}$. New products here not only refer to new products in the general sense, but also include product types and services that individuals have not experienced before. For example, for female consumers who are new mothers, the first purchase of maternal and infant products is also a "new product". Scholars have studied and measured actual innovativeness with different definitions: ownership of new products, purchase of new products, number of new products owned ${ }^{[12]}$, use of new products ${ }^{[13]}$, realization of innovativeness demand.

Steenkamp and Baumgartner divided actual innovativeness into two dimensions: adoption innovativeness and substitution innovativeness. Adoption innovativeness refers to consumers' exploratory acquisition of new products, that is, consumers' actual behavior of adopting new products. Alternative innovativeness refers to the exploratory search for new product related information by consumers, that is, the process of consumers communicating and obtaining new product related information through mass media (advertising) and word-of-mouth. In addition to advertising and word-of-mouth, Im also proposed a third component of alternative Innovativeness: imitation.

\section{The relevance of three concepts of consumer innovativeness}

\section{1 innate innovativeness and actual innovativeness}

Hirschman proposed the contingency model of consumer innovativeness integration ${ }^{[7]}$. He believed that the inherent novelty seeking tendency of consumers, that is, innate innovativeness, would affect the realization of novelty seeking behavior or access to new product information. 
This section mainly summarizes the domestic and foreign research on innate innovativeness and actualized innovativeness.

In terms of adoption innovativeness, Sunmmers found that product adoption behavior depends on contextual variables and consumer characteristics. Innate innovativeness, as a general characteristic of consumers in the initial stage of new product adoption, has a certain correlation with the innovativeness of new product adoption. According to different motivations, innate innovativeness is manifested as stimulating demand, independent demand, pursuing novelty demand and unique demand. These four performances affect the different innovativeness stages of consumers. Consumers' pursuit of novelty is related to consumers' pursuit of novelty, which affects the initial stage of the adoption process; while consumers' independent demand is related to consumers' evaluation and use of products, which affects the later stage of the adoption process. There are different motivations in the two dimensions of innate innovativeness, so the thinking and behavior stimulated are also different. There are always differences between cognitive innovators and perceptual innovators in innovativeness tendency. Cognitive innovators are more inclined to the actual adoption of products, while perceptual innovators are less likely to obtain new information through the actual adoption of new products, because it requires higher cognitive processing. In addition, innovativeness diffusion theory believes that the spread of product related information will affect the diffusion speed of new products. Innovative consumers can show their personality characteristics by participating in alternative innovativeness (specifically, word-of-mouth, advertising and imitation), that is, innate innovativeness, and ultimately drive their specific adoption behavior. Im confirmed this point through empirical research: substitution innovativeness mediates the relationship between innate innovativeness and adoption innovativeness $^{[3]}$.

In the aspect of alternative innovativeness, scholars study the relationship between innate innovativeness and alternative innovativeness from two dimensions of innate innovativeness. Perceptual innovators like to process information through visual and linguistic stimulation, which stimulates the tendency of acquiring new information. However, cognitive innovators have a high demand for cognition, and only obtaining information about new products can not meet their cognitive needs. Hironyawipada and Paswan concluded that perceived innovativeness is positively correlated with alternative innovativeness, while cognitive innovativeness has nothing to do with alternative innovativeness.

\section{2 special fields innovativeness and actualized innovativeness}

From the different research results of the relationship between innate innovativeness and new product adoption behavior, it can be found that innate innovativeness can not explain the adoption behavior of different product types, and many researches focus on the innovativeness in special areas instead of innate innovativeness. Citrin found that innovativeness in special areas has a positive impact on consumers' online shopping adoption, ${ }^{[14]}$ and innovativeness in special areas mediates the correlation between Internet use frequency and consumers' online shopping. Blake conducted a cross-border study and found that in the context of online shopping, the more innovative consumers in special areas are, the higher the frequency of purchasing new products and the wider the scope of purchasing. Hirunyawipada and Paswan concluded that special fields innovativeness is positively related to adoption innovativeness and substitution innovativeness.

\section{3 innate innovativeness and special fields innovativeness}

Innate innovativeness and special innovativeness are two concepts of consumer innovativeness, which are different and related. Individual traits at higher levels of abstraction (such as global innovativeness) may have a significant impact on related traits at lower levels of abstraction (such as innovativeness in special fields). Goldsmith found that there is a significant positive correlation between innovativeness in special fields and innate innovativeness $^{[15]}$. The higher the innate innovativeness of consumers, the higher the innovativeness of a particular product category. In addition, Midgley and Dowling pointed out that interest in specific product categories and social networks mediates the relationship between innate innovativeness and new product adoption. By further subdividing the dimension of innate innovativeness, Hirunyawipada and Paswan found that innovativeness in special fields mediates the relationship between cognitive innovativeness and new product adoption and new product related information search.

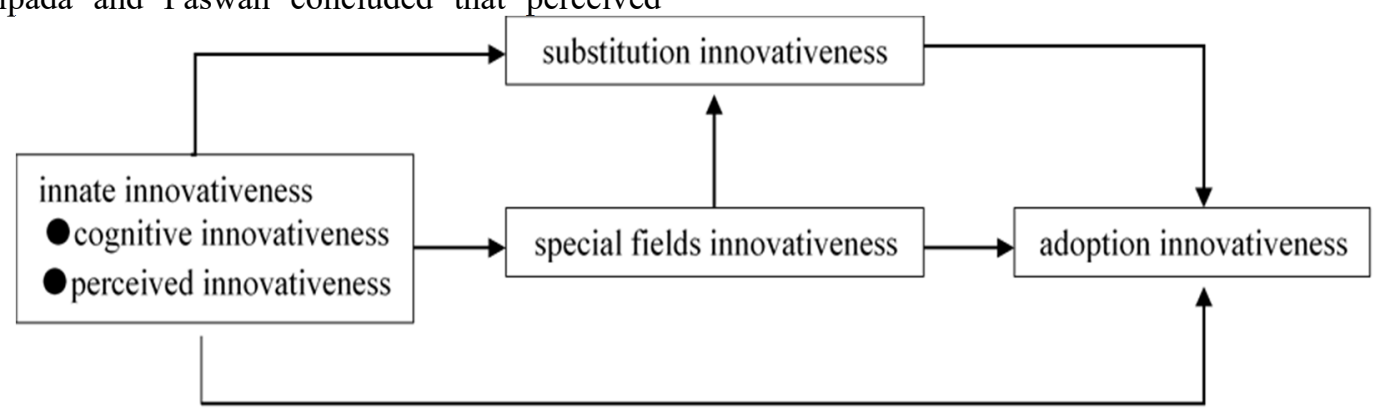

Figure. 1. The function model of consumer innovativeness three concepts 


\section{Future research prospects}

This paper mainly summarizes the domestic and foreign scholars' understanding of the three concepts of consumer innovativeness and the influencing factors, and expounds the relationship between the three concepts of consumer innovativeness. Based on the above analysis and elaboration, we can find that there is no consensus on the definition of consumer innovativeness. Although the existing research has made some valuable achievements, due to the different definitions of consumer innovativeness, the research results will be different, and there are many problems to be solved. Based on the above analysis, this paper puts forward the following research prospects.

First, many studies have proved that for different product areas, the impact of consumer innovativeness on purchase intention presents three different results: positive, negative and irrelevant. Most of the existing studies focus on the positive impact mechanism of consumer innovativeness, but few studies explore the negative impact of consumer innovativeness on purchase intention. What causes this negative effect, and why it produces different results in this product field, need to be further explored.

Second, consumer innovativeness is a strong transnational attribute definition, such as national culture, lifestyle and so on, which has a strong correlation with consumer innovativeness. At present, most of the research is carried out in western countries. The next research can try to verify the previous research results of western countries in the Asian market, and strengthen the localization research.

Thirdly, the multi-dimensional definition of consumer innovativeness is lack of systematic collation and research in the academic community, the measurement standards of each measurement scale have not reached a unified understanding, lack of standardization, and there are defects in different dimensions. After the research, we can integrate and solve its defects based on the existing measurement scale, so as to build a comprehensive and unified measurement scale and improve its prediction accuracy.

\section{Acknowledgments}

Project Supported by Social Science Planning Program of Chongqing (2016BS033); Project Supported by Social and Scientific Research Program of Chongqing Municipal Education Commission (17SKG096); Project Supported by Scientific and Technological Research Program of Chongqing Municipal Education Commission (KJ1600612).

\section{References}

1. Midgley D F, Dowling G R. Innovativeness: The Concept and Its Measurement[J]. Journal of Consumer Research, 1978, 4(4):229.
2. Midgley D F, Dowling G R. Innovativeness: The Concept and Its Measurement[J]. Journal of Consumer Research, 1978, 4(4):229.

3. Midgley D. F., Dowling G.R..A longitudinal study of product form innovation: the interaction between predispositions and social messages [J]. Journal of Consumer Research, 1993, 19(4): 611-625.

4. Steenkamp J. B. E. M., Baumgartner H.. The role of optimum stimulation level in exploratory consumer behavior[J]. Journal of Consumer Research, 1992, 19(3): 434-448.

5. Tellis G J, Yin E, Bell S. Global Consumer Innovativeness: Cross-Country Differences and Demographic Commonalities[J]. Journal of International Marketing, 2009, 17(2):1-22.

6. Steenkamp J B E M, Ter Hofstede F, Wedel M. A Cross-National Investigation into the Individual and National Cultural Antecedents of Consumer Innovativeness[J]. Journal of Marketing, 1999, 63(2): 55-69.

7. Rogers E. M., Shoemaker F. F..Communication of innovations [M]. New York, The Free Press, 1971.

8. Goldsmith R, Reinecke Flynn L. Identifying Innovators in Consumer Product Markets[J]. European Journal of Marketing, 1992, 26(12):42-55.

9. Varma Citrin A, Sprott D E, Silverman S N, et al. Adoption of Internet shopping: the role of consumer innovativeness[J]. Industrial Management \& Data Systems, 2000, 100(7):294-300.

10. Goldsmith R E, Goldsmith F E B. Innovative Consumers and Market Mavens[J]. Journal of Marketing Theory and Practice, 2003, 11(4):54-65.

11. Clark R A, Goldsmith R E. Interpersonal influence and consumer innovativeness[J]. International IJC, 2005, 30(1):34-43.

12. Foxall G. R.. Consumer innovativeness: noveltyseeking, creativity, and cognitive style $[\mathrm{J}]$. Research in Consumer Behavior, 1988(3): 79-113.

13. Cotte J, Wood S L. Families and Innovative Consumer Behavior: A Triadic Analysis of Sibling and Parental Influence[J]. Journal of consumer research, 2004, 31(1): p.78-86.

14. Varma Citrin A, Sprott D E, Silverman S N, et al. Adoption of Internet shopping: the role of consumer innovativeness[J]. Industrial Management \& Data Systems, 2000, 100(7): 294-300.

15. Goldsmith R E, Freiden J B, Eastman J K. The generality specificity issue in consumer innovativeness research[J]. Technovation, 1995, 15(10): 601-612. 